\title{
CEREBRAL X-LINKED ADRENOLEUKODYSTROPHY
}

\section{Follow-up with magnetic resonance imaging}

\author{
Emerson L. Gasparetto, Juliana Mecunhe Rosa, \\ Taísa Davaus, Arnolfo de Carvalho Neto
}

\begin{abstract}
Objective: To report a case of childhood cerebral X-linked adrenoleukodystrophy (X-ADL), emphasizing the magnetic resonance imaging (MRI) findings at initial evaluation and at the follow-up. Case report: Five year-old boy, who was asymptomatic, presented with diagnosis of X-ADL for MRI evaluation. The initial brain MRI showed a focal area of enhancement at the splenium of the corpus calosum. One year later, the follow-up MRI showed a prog ression of the corpus calosus lesion, as well as other lesions in the parietal and occipital lobes. Conclusion: The brain MRI follow-up of patients with X-ADL is important to show the progression of the lesions.
\end{abstract}

KEY WORDS: childhood cerebral X-linked adrenoleukodystrophy, magnetic resonance imaging.

\begin{abstract}
Adrenoleucodistrofia ligada ao X: acompanhamento por ressonância magnética
RESUMO - Objetivo: Relatar um caso de adrenoleucodistrofia ligada ao X (X-ADL), enfatizando os achados de ressonância magnética (RM) na avaliação inicial e no seguimento. Descrição do caso: Paciente masculino de cinco anos de idade, assintomático, com diagnóstico de X-ADL, apresentou-se para estudo de RM. O exame inicial mostrou uma área focal de realce no esplênio do corpo caloso. Após um ano, a RM de seguimento evidenciou aumento da lesão do corpo caloso, assim como novas lesões nos lobos occipitais e parietais. Conclusão: O seguimento por RM de pacientes com X-ADL é importante para a demonstração da progressão das lesões.
\end{abstract}

PALAVRAS-CHAVE: adrenoleucodistrofia ligada ao $\mathrm{X}$, ressonância magnética.

X-linked adrenoleukodystrophy (X-ADL) is a genetically determined rare metabolic progressive disorder, which involves the central nervous system (CNS), adrenal cortex and testicles. It is related to accumulation of very-long-chain fatty acids in plasma and tissues, caused by a deficient peroxisomal membrane p rotein. The clinical manifestation has a wide variety within two major forms; the childhood cerebral form, causing a severe disability that leads to death early; and the adrenomyeloneuropathy, a milder adult form witch involves mainly the spinal cord and peripheral nerves, presenting a slow prog ression with better prognostic. The bone marrow transplantation (BMT) is the only effective long-term treatment for $X$-ADL disease, however must be performed at an early stage of cerebral disease ${ }^{1,2}$. Brain magnetic re sonance imaging (MRI) is an essential tool to evaluate patients with X-ADL. It allows early detection of CNS lesions, and the serial follow-up aids to predict the prognosis of the disease and monitoring therapeutic interventions. MRI changes are caused by an inflammatory demyelization process resulting in prolongation of $\mathrm{T} 1$ and $\mathrm{T} 2$ relaxation times. Areas of involvement are best seen as foci of hyperintense signal on T2-wheighted images, with or without enhancement after contrast administration ${ }^{3}$. Loes et al. ${ }^{4}$ suggested a severity score for brain MRI of patients with X-ADL based on the location and extension of the lesions, as well as considering the presence of focal and/or global atrophy comparing serial MRI exams. It consists in a point system (0 to 34) where each area is scored as 0 if normal; 0.5 if unilateral or if the involvement is questionable and the patient had no other abnormalities; and 1 if the lesion or at rophy is bilateral; a score of $\geq 1$ is considered abnormal. The MRI severity scale used in combination with neuropsychologic and neurologic parameters, may im prove the characterization of the disease prog res-

Discipline of Diagnostic Radiology, Department of Internal Medicine, University of Paraná (ELG, JMR, TD, ACN) and DAPI - Diagnóstico Avançado Por Imagem (ACN), Curitiba PR, Brazil.

Received 22 February 2006, received in final form 20 July 2006. Accepted 5 September 2006.

Dr. Arnolfo de Carvalho Neto - DAPI - Diagnóstico Avançado Por Imagem - Rua Brigadeiro Franco 122 - 80430-210 Curitiba PR Brasil. E-mail: arnolfocarvalho@hotmail.com 
sion. The characteristic MRI features of childhood cerebral X-linked ALD have been well documented. However, there are few reports discussing the MRI findings at serial follow-up evaluation.

The aim of this article is to report a case of childhood cerebral X-ADL, emphasizing the MRI findings at initial evaluation and at the follow-up MRI.

\section{CASE}

A five years-old boy, who was asymptomatic, presented with diagnosis of X-ADL for MRI evaluation. The neurological examination was normal. He had a positive familiar history of X-ALD (two maternal uncles) and the diagnosis was confirmed at the birth by biochemical and genetic methods. No previous treatments were referred.

The initial brain MRI showed a focal area of high signal on T2-weighted images and enhancement after contrast administration at the splenium of the corpus calosum (Fig 1). The patient was scored one following the Loes's criteria 4 .
One year later the patient retuned to perform the follow-up MRI. At this time he remained asymptomatic, with normal neurological examination. The MRI demonstrated a reas of high signal on T2-w eighted images with peripheral enhancement after contrast administration on the splenium of the corpus calosum, as well as on the white matter of the parietal and occipital lobes (Fig 2). The lesion at the corpus calosum was considerably large in this second MRI. The patient was then scored as three considering the Loes's criteria ${ }^{4}$ and he was referred to the bone marrow transplantation (BMT) unit of the Hospital de Clínicas of the University of Paraná for evaluation. At this moment, the parents agreed with the publication of the case and signed the consent.

\section{DISCUSSION}

Childhood cerebral X-linked ALD is the most frequently and severe form of ALD, being present in $35 \%$ to $40 \%$ of boys with the biochemical diagnosis of X-ALD. Patients usually show normal development

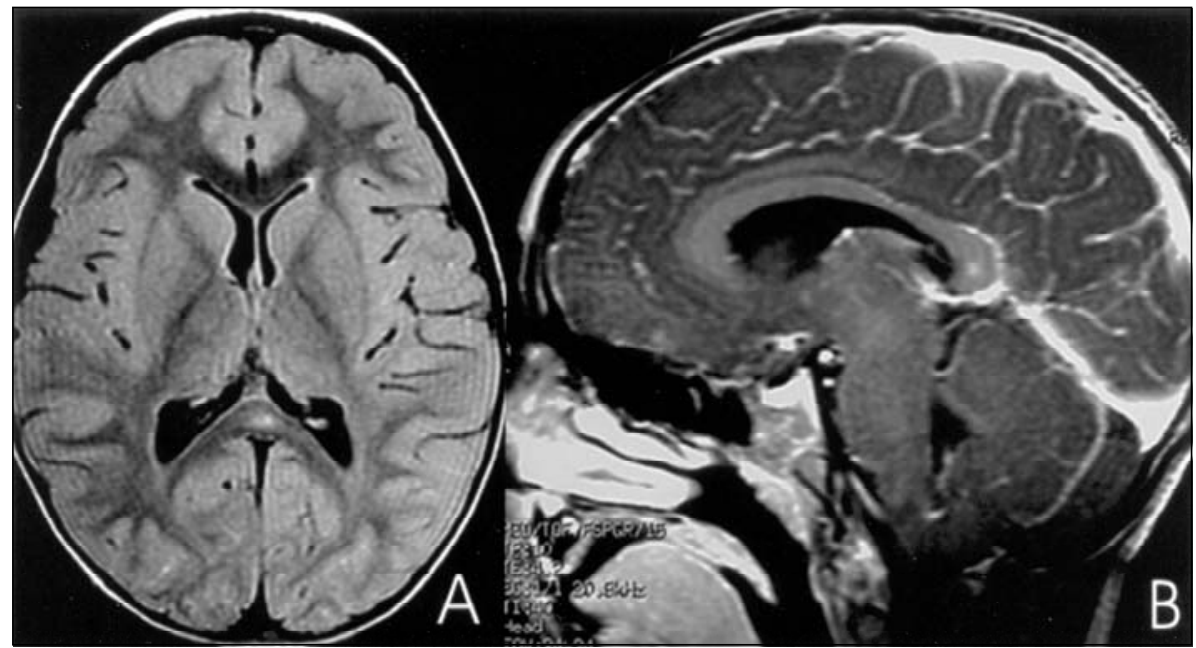

Fig 1. Axial FLAIR (A) and sagital T1-weighted MRI after contrast administration ( $B$ ) demonstrate a focal area of high signal in the splenium of corpus calosum, which shows enhancement after contrast administration.
Fig 2. Axial FLAIR (A) and axial T1weighted MRI after contrast administration (B) show progres sion of the corpus calosum lesion, as well as other lesions in the pari etal white matter.

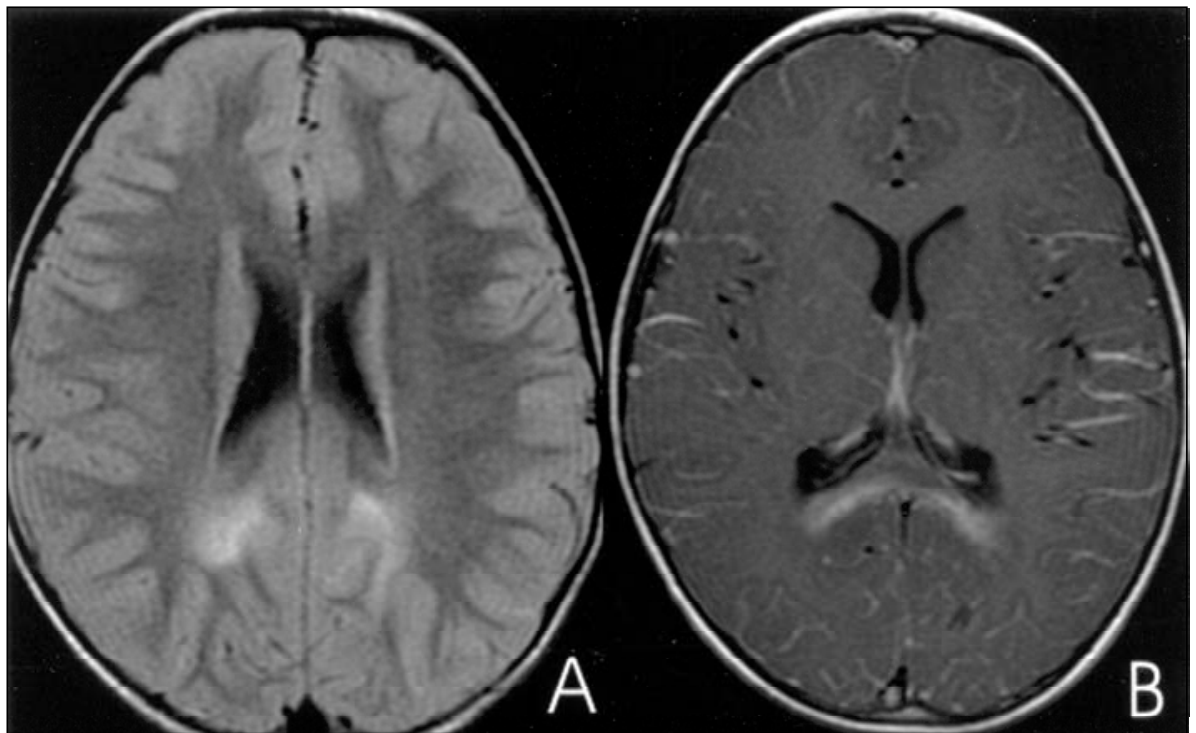


until 4-10 years of age. Clinical manifestations are characterized by adrenal insufficiency and neurological deterioration that leads to death within months to years ${ }^{1}$. BMT can an effective way of treatment, which can achieve long term stabilization for patients who are at risk of rapid prog ression, only if underwent at an early enough stage ${ }^{1,2}$. The monitoring of asymptomatic patients with noninvasive neuro ima ging and neuropsychological studies may conduct to the early detection of cerebral involvement ${ }^{1}$. In the p resent case, the diagnosis of X-ADL was based on biochemical and genetic methods. The investigation was performed because the familiar history of X-ADL (two maternal uncles).

MRI is essential for both initial and follow-up evaluation of childhood cerebral X-linked ALD. The CNS characteristics lesions include extensive demyelization in the periventricular deep white matter, cavitations, and perivascular lymphocyte infiltrates. The white matter demyelization most often begins in the parietal and occiptal regions and pro g ress to the anterior and lateral regions. The follow-up MRI may show improvement, stabilization, or aggravation of the lesions ${ }^{5}$. In our case, the initial MRI showed a small lesion in the splenium of the corpus calosum, and the follow-up MRI demonstrated enlargement of this lesion, as well as the presence of other lesions in the parietal and occipital lobes.

A MRI severity scale score for patients with X-ADL was proposed by Loes et al. ${ }^{4}$, based on the location and extension of the lesions, and presence of focal and/or global atrophy. The scale consists in a point system (0 to 34$)$, where each region of the brain is scored as 0 if normal; 0.5 if there is an unilateral lesion or if the involvement is questionable and the patient had no other abnormalities; and 1 if the lesion or atrophy is bilateral. The present case was scored as one at the initial evaluation, considering the corpus calosum lesion, and as three on the followup MRI because of the several brain abnormalities.

Emerging MRI techniques such as proton MR spectroscopy identify impending or beginning lesions that still appears normal on conventional MRI. It can be considered suitable for the prediction of lesion progression on MRI in X-ADL. According to Eichler at al. ${ }^{6}$, a $\mathrm{N}$-acetylaspartate (NAA) to choline ratio in norm a I appearing white matter of less than 5.0 is strongly predictive of subsequent lesion progression on MRI.
Loes et al.7 rep orted five patterns of X-ADL based on the anatomic location, age of the patient and initial MRI severity scale score. The suggested that those patterns could allow predicting the disease prog re ssion. Pattern 1, the most common, was defined as primary involvement of posterior white matter, mainly on boys younger than 10 and has resened prognosis especially if contrast enhancement is present and if the abnormalities show up at an early age. The second most common (pattern 2) in the 10- to 16year-old patients has a frontal involvement, the pro$g$ ression vary with the age and severity score but also with a bad prognosis. The pattern 3 , most common in adults, involving the frontopontine or corticospinal projection fibers, and pattern 4 , which primarily involves the cerebellum in late teenage years, have both a much slower progression. Pattern 5 defined as combined but separate parieto-occciptal and frontal white matter lesions at an early age progressed very rapidly. Our case presented with the Loes's pattern 1. The initial MRI was scored as one and the follow-up MRI, one year late, as three.

In conclusion, patients with childhood cerebral Xlinked ALD may present areas of high signal on T2weighted images and enhancement after contrast administration. These lesions usually predominate in the splenium of the corpus calosum and in the parieto-occipital regions. The application of the Loes's criteria is important at the initial MRI evaluation of patients with X-ADL, as well as it is helpful in the follow-up of affected patients.

\section{REFERENCES}

1. Peters C, Charnas RL, Tan Y, et al. Cerebral X-linked adrenoleukodyst rophy: the international hematopoietic cell transplantation experience from 1982 to 1999. Blood 2004;104:1881-1888

2. Loes DJ, Stillman AE, Hite S, et al. Childhood cerebral form of adrenoleukodystrophy: short-term effect of bone marrow transplantation on brain MR observations. AJNR 1994;15:1767-1771.

3. Melhem ER, Loes DJ, Georgiades CS, Raymond GV, Moser HW. Xlinked adrenoleukodystrophy: the role of contrast-enhanced MR imaging in predicting disease progression. AJNR 2000;21:839-844.

4. Loes DJ, Hite S, Moser H, et al. Adrenoleukodystrophy: a scoring method for brain MR observations. AJNR 1994;15:1761-1766.

5. Kim JH, Kim HJ. Childhood X-linked Adrenoleukodystrophy: clinicalpathologic overview and MR imaging manifestation at initial evaluation and follow-up. RadioGraphics 2005;25:619-631.

6. Eichler FS, Barker PB, Cox C, et al. Proton MR spectroscopic imaging predicts lesion progression on MRI in X-linked adrenoleukodystrophy. Neurology 2002;58:901-907.

7. Loes DJ, Fatemi A, Melhem ER, et al. Analysis of MRI patterns aids p rediction of progression in X-linked adrenoleukodystrophy. Neurology 2003;61:369-374. 